\title{
Metal-Free Visible-Light-Mediated Hydrotrifluoromethylation of Unactivated Alkenes and Alkynes in Continuous Flow
}

\begin{abstract}
We report herein a novel photoredox-catalyzed hydrotrifluoromethylation of unsaturated systems under continuous flow. This metal-free method is easily broadened to other perfluoroalkyl groups $\left(\mathrm{R}_{\mathrm{F}}=\mathrm{CF}_{3}, \mathrm{CFCl}_{2}, \mathrm{CF}_{2} \mathrm{Br}, \mathrm{C}_{4} \mathrm{~F}_{9}\right)$ thanks to the use of sulfilimino iminiums as sources of $R_{F}$ radicals. The mild reaction conditions are compatible with unactivated alkenes bearing a wide range of functionalities, as well as with alkynes for the first time.
\end{abstract}

Anne-Laure Barthelemy, Guillaume Dagousset, ${ }^{*}$ and Emmanuel Magnier*
Due to the specificities of the fluorine atom, the introduction of a trifluoromethyl group into organic compounds has a dramatic impact on the physicochemical and biological properties of these molecules. It has undoubtedly triggered the development of a wide range of efficient methods to synthesize trifluoromethylated compounds, notably via nucleophilic or electrophilic trifluoromethylations. ${ }^{[1]}$ Concerning radial approaches, visiblelight photoredox catalysis has recently established itself as one of the most efficient methodology to perform trifluoromethylation reactions. ${ }^{[2,3]}$ However, in classical batch conditions using standard glassware, one potential drawback of such procedures is that visible light is rapidly absorbed on a millimeter scale, according to Beer-Lambert-Bouguer's law. Therefore, the desired reaction can only occur near the surface of the flask, in a very small volume compared to the total reaction mixture. As a consequence, prolonged irradiation time is needed to go until complete conversion. This may lead to the formation of undesired side-products, and this limitation is clearly amplified in the case of large-scale experiments.

To circumvent this issue, continuous flow has recently appeared as the technique of choice to perform photochemical reactions. ${ }^{[4]}$ Indeed, the narrow tubing of flow reactors allows for a homogeneous and optimal irradiation of the reaction mixture, thanks to a very high surface-to-volume ratio. Regarding the trifluoromethyl group, pioneer studies were successfully reported by the groups of Noël[5] and Stephenson. ${ }^{\left[{ }^{[6]}\right.}$ Efforts were mainly focused on the $\mathrm{C}-\mathrm{H}$ trifluoromethylation of (hetero)arenes ${ }^{[5 a-b, f-g, 6]}$ or thiols. ${ }^{[5-e-, 7]}$ Surprisingly, to the best of our knowledge, only one example of trifluoromethylation of alkenes was recently reported by Noël and coworkers. ${ }^{[8-10]}$ Although good yields and high $E$ selectivity were achieved, the reaction was limited to styrene derivatives and an expensive Ir-based photocatalyst was used. Therefore, the development of a general metal-free continuous-flow method that would be compatible with unactivated alkenes is highly desirable. ${ }^{[11]}$ In addition, if alkynes are substrates of choice for photoredox-catalyzed trifluoromethylation in batch, ${ }^{[11 a, 11 c, 12]}$ analogous reactions in flow have not been reported yet, to the best of our knowledge. We wish to report herein a new and efficient hydrotrifluoromethylation of unactivated alkenes in flow. This

\footnotetext{
A.-L. Barthelemy, Dr. G. Dagousset, Dr. E. Magnier

Institut Lavoisier de Versailles, UMR 8180, Université de Versailles-Saint-

Quentin 78035 Versailles Cedex, France

Fax: (+) 33139254452
}

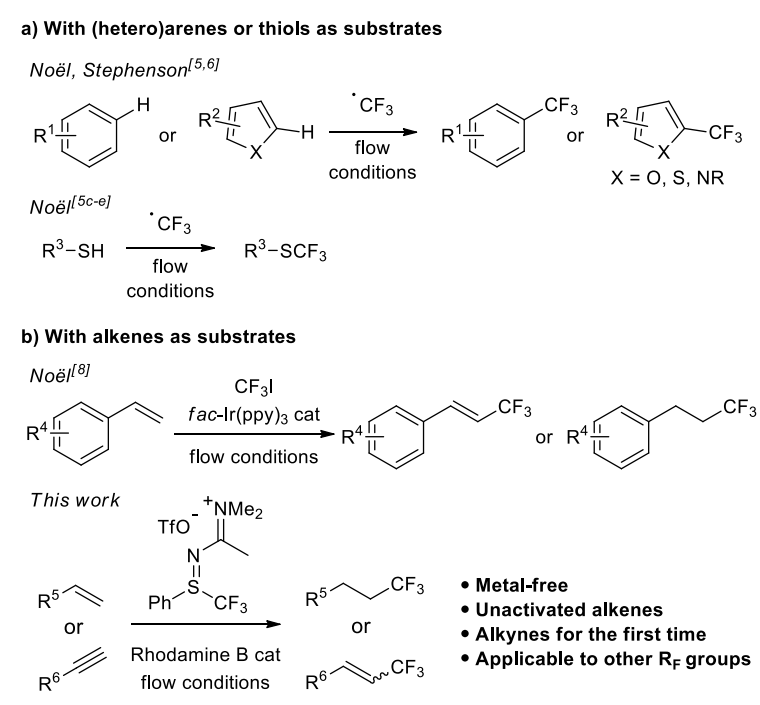

Scheme 1. Main developments in continuous-flow photoredox-catalyzed trifluoromethylation reactions.

metal-free process has been successfully extended to other perfluoroalkyl groups, and for the first time to alkynes as substrates.

We recently disclosed the use of fluorinated sulfilimino iminiums 1 as new sources of perfluoroalkyl radicals under photoredox catalysis. ${ }^{[13]}$ Based on this experience and on our recent work on continuous-flow photocatalyzed reactions, ${ }^{[14]}$ we envisioned that these reagents, easily prepared in one step from the corresponding sulfoxide at a multi-gram scale, would be suitable partners to perform hydroperfluoroalkyation of alkenes. Indeed, when alkene $\mathbf{2 a}$ was treated with 1 equiv of $\mathrm{CF}_{3}$-sulfilimino iminium 1a, 2 equiv of Hantzsch ester $3(\mathrm{HE})$ as $\mathrm{H}$ atom source, and Rhodamine 4 as photocatalyst ( $5 \mathrm{~mol} \%$ ) with a flow rate of $0.5 \mathrm{~mL} \cdot \mathrm{min}^{-1}$ under green LEDs irradiation, the corresponding adduct 5 a was obtained in $50 \%$ yield (Table 1, entry 1 ). Encouraged by this result, the reaction parameters were then optimized, including the flow rate (entries 3-4), the solvent (entry 5 ), the stoichiometry of reagents and catalyst (entries 6-7,10), and the concentration of the reaction mixture (entries 8-9). Finally, the best conditions were found by dissolving alkene $\mathbf{2 a}$ with 1.5 equiv of 1a, 2.7 equiv of 3 and $5 \mathrm{~mol} \%$ of photocatalyst 4 in $\mathrm{CH}_{2} \mathrm{Cl}_{2}(0.025 \mathrm{M})$, with a flow rate of $1 \mathrm{~mL} \cdot \mathrm{min}^{-1}$ (entry 7$) .{ }^{[15]}$ With these mild reaction conditions in hand, the scope of this hydrotrifluoromethylation was next investigated, and the results are summarized in Scheme 2. First, sulfilimino iminiums 1b-1d with other perfluoroalkyl groups $\left(\mathrm{R}_{\mathrm{F}}=\mathrm{CF}_{2} \mathrm{Br}, \mathrm{CFCl}_{2}\right.$ and $\mathrm{C}_{4} \mathrm{~F}_{9}$, respectively) were also suitable partners for this reaction, giving access to the expected monofluoromethyl, difluoromethyl and perfluoroalkyl adducts 5 ab-5ad in up to $60 \%$ yield. Pleasingly, a wide number of mono-substituted or 1,1-disubstituted alkenes $\mathbf{2 b}-\mathbf{2} \mathbf{g}$ bearing a variety of functional groups (ether, carbamate, 
Table 1. Survey of reaction conditions for the photoredox-catalyzed hydrotrifluoromethylation of alkene 1 a.

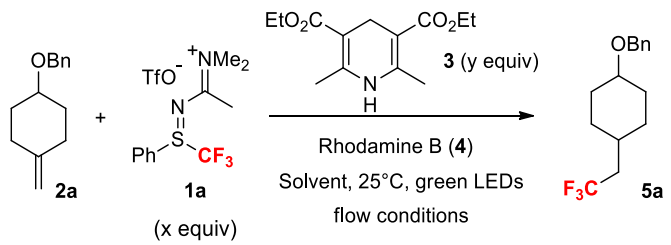

\begin{tabular}{llllll}
\hline Entry & $x ; y$ & Solvent & $\begin{array}{l}\text { Flow rate } \\
\left(\mathrm{mL} . \mathrm{min}^{-1}\right)\end{array}$ & $\begin{array}{l}\text { Residence } \\
\text { time }\left(\mathrm{t}_{\mathrm{R}}\right)\end{array}$ & Yield [\%] $]^{[a, b, c]}$ \\
\hline 1 & $1 ; 2$ & $\mathrm{DCE}$ & 0.5 & $20 \mathrm{~min}$ & 50 \\
2 & $1.5 ; 3$ & $\mathrm{DCE}$ & 0.5 & $20 \mathrm{~min}$ & 60 \\
3 & $1.5 ; 3$ & $\mathrm{DCE}$ & 1.0 & $10 \mathrm{~min}$ & 66 \\
4 & $1.5 ; 3$ & $\mathrm{DCE}$ & 2.0 & $5 \mathrm{~min}$ & 62 \\
5 & $1.5 ; 3$ & $\mathrm{CH}_{2} \mathrm{Cl}_{2}$ & 1.0 & $10 \mathrm{~min}$ & 75 \\
6 & $1.5 ; 2.5$ & $\mathrm{CH}_{2} \mathrm{Cl}_{2}$ & 1.0 & $10 \mathrm{~min}$ & 71 \\
7 & $1.5 ; \mathbf{2 . 7}$ & $\mathrm{CH}_{2} \mathrm{Cl}_{2}$ & $\mathbf{1 . 0}$ & $\mathbf{1 0} \mathrm{min}$ & $\mathbf{8 7}(\mathbf{7 6})^{[\mathrm{d}]}$ \\
$8^{[\mathrm{e}]}$ & $1.5 ; 2.7$ & $\mathrm{CH}_{2} \mathrm{Cl}_{2}$ & 1.0 & $10 \mathrm{~min}$ & 47 \\
$9^{[\mathrm{f}]}$ & $1.5 ; 2.7$ & $\mathrm{CH}_{2} \mathrm{Cl}_{2}$ & 1.0 & $10 \mathrm{~min}$ & 63 \\
$10^{[\mathrm{g}]}$ & $1.5 ; 2.7$ & $\mathrm{CH}_{2} \mathrm{Cl}_{2}$ & 1.0 & $10 \mathrm{~min}$ & 72 \\
$11^{[\mathrm{h}]}$ & $1.5 ; 2.7$ & $\mathrm{CH}_{2} \mathrm{Cl}_{2}$ & 1.0 & $10 \mathrm{~min}$ & 0 \\
$12^{[\mathrm{i}]}$ & $1.5 ; 2.7$ & $\mathrm{CH}_{2} \mathrm{Cl}_{2}$ & 1.0 & $10 \mathrm{~min}$ & 0 \\
\hline
\end{tabular}

[a] General conditions: 2a (0.20 mmol), 1a (x equiv), 3 (y equiv), and 4 $(5 \mathrm{~mol} \%)$ in $8 \mathrm{~mL}$ of MeCN irradiated with green LEDs $(525 \mathrm{~nm})$ at $25^{\circ} \mathrm{C}$ inside a $10 \mathrm{~mL}$ reactor of a E-series Vapourtec flow system. See ESI for more details. [b] Yields determined by ${ }^{19} \mathrm{~F}$ NMR spectroscopy using $\mathrm{PhOCF}_{3}$ as an internal standard. [c] d.r. $=1.1: 1$ in all cases. [d] Yield into brackets referred to chromatographically pure product. [e] With $20 \mathrm{~mL}$ of $\mathrm{CH}_{2} \mathrm{Cl}_{2}$ [f] With $4 \mathrm{~mL}$ of $\mathrm{CH}_{2} \mathrm{Cl}_{2}$. [g] With $2.5 \mathrm{~mol} \%$ of 4. [h] Without 4. [i] In the dark. ester, halogen, sulfonic ester, phthalimide, ketone) were smoothly trifluoromethylated by this continuous-flow process, affording the corresponding $\mathrm{CF}_{3}$-adducts $\mathbf{5 b}-\mathbf{5 g}$ in good yields. Importantly, this photocatalyzed reaction was also readily performed with steroid derivatives $\mathbf{2 h}-\mathbf{2} \mathbf{i}$ and with natural compound (+)-Nootkatone $\mathbf{2} \mathbf{j}$, showing that it is easily applicable to the late-stage functionalization of small complex molecules. Encouraged by these results, we next thought to extend the scope of this reaction to alkynes. While aliphatic alkynes such as 1-octyne (6a) gave only poor yield of the corresponding trifluoromethylated alkene (22\% NMR yield for $7 \mathrm{a}$ ), we were pleased to see that aromatic alkynes $\mathbf{6 b}-\mathbf{6 f}$ bearing electrondonating (OMe, OPh, $\mathrm{NHCbz})$ or -withdrawing groups $\left(\mathrm{CO}_{2} \mathrm{Me}\right)$ were efficiently trifluoromethylated under the same reaction conditions (flow rate of $1 \mathrm{~mL} \cdot \mathrm{min}^{-1}, t_{R}=10 \mathrm{~min}$ ). This difference of reactivity between aliphatic and aromatic alkynes could not be rationalized. However, it is worth to note that similar reactions in batch are carried out with aliphatic alkynes, while aromatic alkynes are usually unreactive substrates. ${ }^{[11 \mathrm{a}, 11 \mathrm{c}, 12 \mathrm{~b}-\mathrm{d}]}$

Importantly, the reaction with alkyne 7 e could be carried out on a ten-fold higher scale $(2 \mathrm{mmol})$ without any decrese in yield. This demonstrated the practicity and efficiency of continuous-flow photocatalysis to perform large-scale experiments with a significant throughput (1.5 mmol. $\left.\mathrm{h}^{-1}\right)$.

In order to gain some insight into the mechanism of this hydroperfluoroalkylation process, some control experiments were performed. Both the light and the photocatalyst $\mathbf{4}$ were essential parameters for the reaction to proceed (Table 1, entries 11-12), which suggested that a radical pathway was involved. Moreover, some luminescene quenching experiments were carried out (Scheme 3a). The rate of quenching determined using Stern-Volmer plots showed that a reductive quenching cycle involving the oxidation of Hantzsch ester 3 by the excited state $4^{*}$ of Rhodamine $B$ was favoured over an

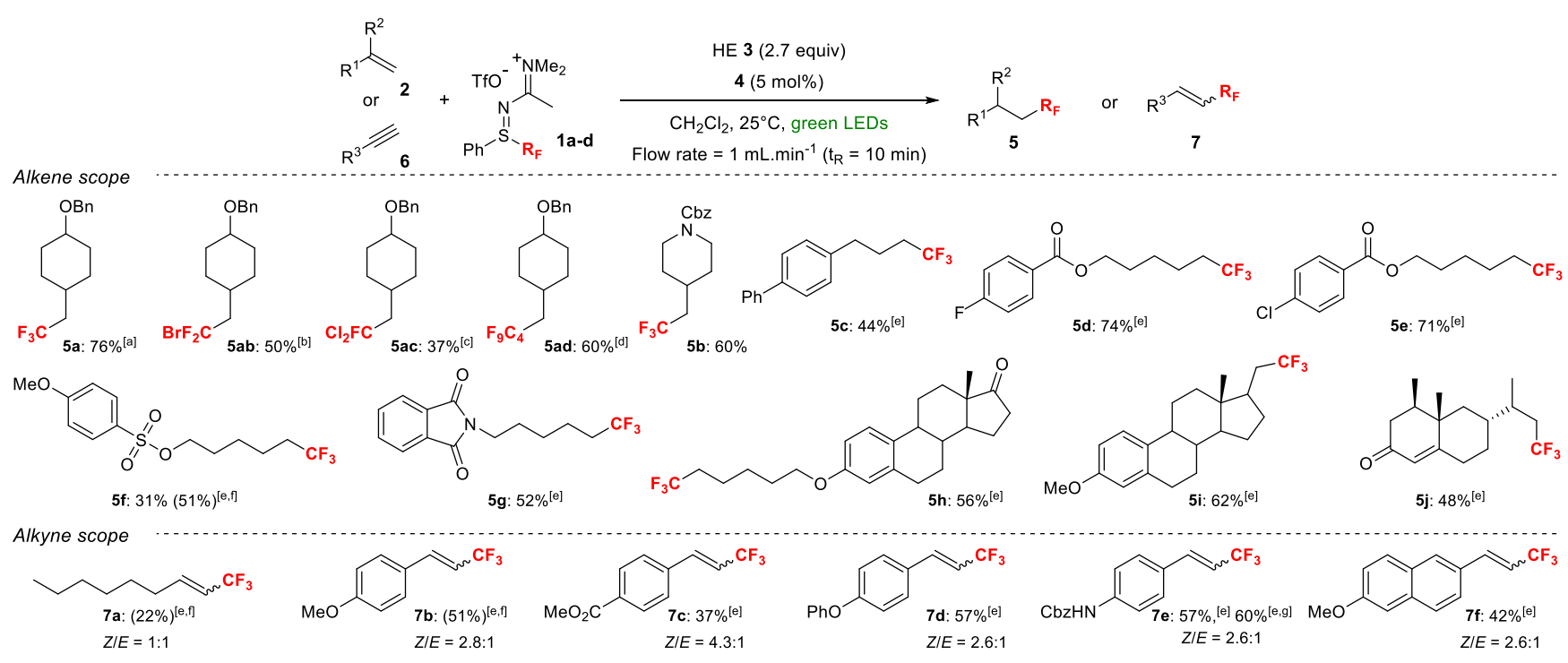

Scheme 2. Scope of hydroperfluoroalkylation of alkenes and alkynes in flow. General Conditions: alkene 2 or alkyne 6 (0.2 mmol), 1 (0.3 mmol), Hantzsch ester 3 $(\mathrm{HE}, 0.54 \mathrm{mmol}), 4(5 \mathrm{~mol} \%)$ in $8 \mathrm{~mL}$ of $\mathrm{CH}_{2} \mathrm{Cl}_{2}$ at $25^{\circ} \mathrm{C}$. Flow rate of $1 \mathrm{~mL}$. $\mathrm{min}^{-1}\left(\mathrm{t}_{\mathrm{R}}=10 \mathrm{~min}\right)$ under green LED irradiation. Yield refer to chromatographically pure product. [a] d.r. $=1.1: 1$. [b] d.r. $=1: 1$. [c] d.r. $=1: 1$. [d] d.r. $=2: 1$. [e] With 3 equiv of $1 \mathrm{a}$ and 3 equiv of 3 . [f]Yields into brackets determined by ${ }^{19} \mathrm{~F}$ NMR spectroscopy using $\mathrm{PhOCF}_{3}$ as an internal standard. [g] Reaction performed on a 2 mmol scale. d.r. = diastereomeric ratio. 
oxidative quenching cycle (i.e. direct reduction of 1 by $4^{\star}$ ).

Based on this analysis and on previous Electron Paramagnetic Resonance experiments with sulfilimino iminiums $\mathbf{1}^{\left[{ }^{[13]}\right.}$ a plausible mechanism is depicted in Scheme $4 \mathrm{~b}$. After irradiation with visible light, the formed excited state $4^{\star}$ oxidizes HE 3 . The highly reductive species $4^{-}$- generated reacts with 1 to form the corresponding $\cdot \mathrm{R}_{\mathrm{F}}$ radical $\mathbf{A}$, which subsequently adds onto alkene 2 (or alkyne 6). Final HAT (Hydrogen atom transfer) of the formed radical intermediate $\mathbf{B}$ with HE $\mathbf{3}$ would lead to the desired perfluoroalkylated adduct $\mathbf{5}$ (or 7). ${ }^{[16]}$
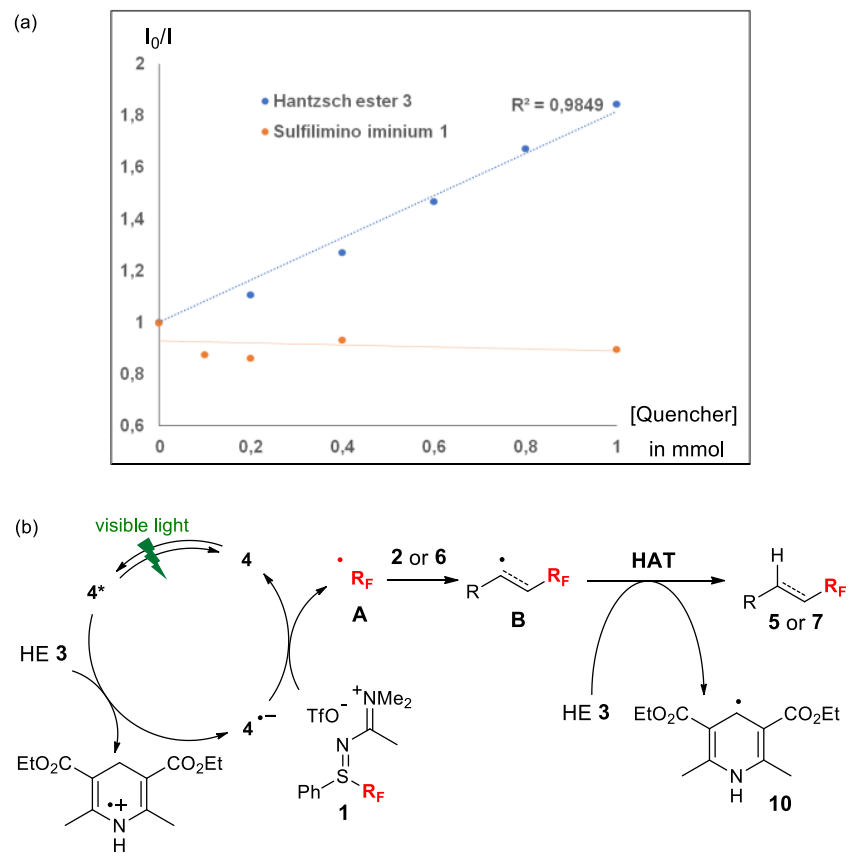

Scheme 3. (a) Luminescence quenching experiments. Stern Volmer plots $\mathrm{I} / \mathrm{I}=\mathrm{f}([$ quencher] $)$. (b) Proposed mechanism.

In conclusion, we have successfully developed a novel photoredox-catalyzed hydroperfluoroalkylation protocol under continuous-flow conditions, which uses sulfilimino iminiums as versatile sources of perfluoroalkyl radicals. This process is quite efficient (residence time of $10 \mathrm{~min}$ ) and tolerates a large array of functional groups. Importantly, both alkenes and alkynes were smoothly perfluoroalkylated under these mild and metal-free reaction conditions. Extension of this work to other perfluoroalkylation reactions is currently underway in our laboratory and will be reported in due course.

\section{Experimental Section}

General procedure: In a dry tube under argon were added the sulfilimino iminium 1 ( $0.3 \mathrm{mmol}, 1.5$ equiv), Hantzsch Ester 3 (0.54 mmol, 2.7 equiv), Rhodamine B 4 (0.01 mmol, $5 \mathrm{~mol} \%)$ and the alkene $2(0.2$ mmol, 1 equiv). $\mathrm{CH}_{2} \mathrm{Cl}_{2}(8 \mathrm{~mL})$ was added and the solution is degazed with argon and stirred at room temperature until complete dissolution of Hantzsch ester 3. Then, using an easy-Photochem E-series system from Vapourtec with a $10 \mathrm{~mL}$ reactor irradiated with a green $525 \mathrm{~nm}$ LED system, $8 \mathrm{~mL}$ of the solution $(0.2 \mathrm{mmol})$ was pumped at a flow rate of $1 \mathrm{~mL} \cdot \mathrm{min}^{-1}$ at $25^{\circ} \mathrm{C}$. After collecting the reaction mixture, a solution of $\mathrm{HCl} 1 \mathrm{M}(10 \mathrm{~mL})$ was added and the solution was extracted with $\mathrm{CH}_{2} \mathrm{Cl}_{2}$ $(2 \times 20 \mathrm{~mL})$. The combined organic layers were dried with $\mathrm{MgSO}_{4}$, filtered and evaporated under reduced pressure. The crude was then purified by prepartive TLC on silica gel to afford the corresponding pure product 5 .

\section{Acknowledgments}

ALB thanks the French Ministry of Research for a doctoral fellowship. LabEx Charmmmat is gratefully acknowledged for the funding of the continuous flow device.

Keywords: flow chemistry • sulfilimino iminium • trifluoromethylation $\cdot$ photoredox catalysis $\cdot$ radicals

[1] a) P. Kirsch in Modern Fluoroorganic Chemistry: Synthesis, Reactivity, Applications, $2^{\text {nd }}$, Completely Revised and Enlarged edition, Wiley: New-York, 2013; b) K. Müller, C. Faeh, F. Diederich, Science 2007, 317,1881 ; c) Bioorganic and Medicinal Chemistry of Fluorine (Eds.: J.P. Begue, D. Bonnet-Delpon), Wiley, Hoboken, 2008; d) J. Wang, M Sanchez-Rosello, J. L. Acena, C. del Pozo, A. E. Sorochinsky, S. Fustero, V. A. Soloshonok, H. Liu, Chem. Rev. 2014, 114, 2432.

[2] For recent reviews on photoredox catalysis, see: a) K. Zeitler, Angew. Chem. 2009, 121, 9969; Angew. Chem. Int. Ed. 2009, 48, 9785; b) T. P. Yoon, M. A. Ischay, J. Du, Nat. Chem. 2010, 2, 527; c) J. M. R Narayanam, C. R. J. Stephenson, Chem. Soc. Rev. 2011, 40, 102; d) F. Teplỳ, Collect. Czech. Chem. Commun. 2011, 76, 859; e) J. Xuan, W.-J. Xiao, Angew. Chem. 2012, 124, 6934. Angew. Chem. Int. Ed. 2012, 51, 6828; f) C. K. Prier, D. A. Rankic, D. W. C. MacMillan, Chem. Rev. 2013, 113, 5322; g) T. Koike, M. Akita, Synlett 2013, 24, 2492; h) D. M. Schultz, T. P. Yoon, Science 2014, 343, 1239176; i) M. D. Kärkäs, B. S Matsuura, C. R. J. Stephenson, Science 2015, 349, 1285.

[3] Selected reviews on photocatalyzed perfluoroalkylations, see: a) $T$. Koike, M. Akita, Top. Catal. 2014, 57, 967; b) H. Egami, M. Sodeoka Angew. Chem. 2014, 126, 8434; Angew. Chem. Int. Ed. 2014, 53, 8294 ; c) S. Barata-Vallejo, S. M. Bonesi, A. Postigo, Org. Biomol. Chem. 2015, 13, 11153; d) G. Dagousset, A. Carboni, G. Masson, E. Magnier, in Modern Synthesis Processes and Reactivity of Fluorinated Compounds; (Eds.: H. Groult, F. Leroux, A. Tressaud), Elsevier, 2016; e) X. Pan, H. Xia, J. Wu, Org. Chem. Front. 2016, 3, 1163; f) E. H. Oh H. J. Kim, S. B. Han, Synthesis 2018, 50, 3346.

[4] Selected reviews: a) J. P. Knowles, L. D. Elliott, K. I. Booker-Milburn, Beilstein J. Org. Chem. 2012, 8, 2025; b) Y. Su, N. J. W. Straathof, V. Hessel, T. Noël, Chem. Eur. J. 2014, 20, 10562; c) Z. J. Garlets, J. D. Nguyen, C. R. J. Stephenson, Isr. J. Chem. 2014, 54, 351; d) M. B. Plutschack, C. A. Correia, P. H. Seeberger, K. Gilmore, Top. Organomet. Chem. 2016, 57, 43; e) D. Cambié, C. Bottecchia, N. J. W. Straathof, V. Hessel, T. Noël, Chem. Rev. 2016, 116, 10276.

[5] a) N. J. W. Straathof, D. J. G. P. van Osch, A. Schouten, X. Wang, J. C. Schouten, V. Hessel, T. Noël, J. Flow Chem. 2014, 4, 12; b) N. J. W. Straathof, H. P. L. Gemoets, X. Wang, J. C. Schouten, V. Hessel, T. Noël, ChemSusChem 2014, 7, 1612; c) N. J. W. Straathof, B. J. P. Tegelbeckers, V. Hessel, X. Wang, T. Noël, Chem. Sci. 2014, 5, 4768; d) N. J. W. Straathof, Y. Su, V. Hessel, T. Noël, Nat. Protoc. 2016, 11, 10; e) C. Bottecchia, X.-J. Wei, K. P. L. Kuijpers, V. Hessel, T. Noël, J. Org. Chem. 2016, 81, 7301; f) Y. Su, K. P. L. Kuijpers, N. König, M.Shang, V. Hessel, T. Noël, Chem. Eur.J. 2016, 22,12295; g) I. Abdiaj, C. Bottecchia, J. Alcazar, T. Noël, Synthesis 2017, 4, 4978; h) X. Zhang, Y. Li, X. Hao, K. Jin, R. Zhang, C. Duan, Tetrahedron 2018, 74, 1742 
[6] a) J. W. Beatty, J. J. Douglas, K. P. Cole, C. R. J. Stephenson, Nat. Commun. 2015, 6, 7919; b) J. W. Beatty, J. J. Douglas, R. Miller, R. C McAtee, K. P. Cole, C. R.J. Stephenson, Chem 2016, 1, 456.

[7] For the photocatalyzed $\alpha$-trifluoromethylation of ketones in flow, see: D. Cantillo, O. de Frutos, J. A. Rincón, C. Mateos, C. O. Kappe Org. Lett. 2014, 16, 896

[8] N. J. W. Straathof, S. E. Cramer, V. Hessel, T.Noël, Angew. Chem. 2016, 128, 15778; Angew. Chem. Int. Ed. 2016, 55, 15549

[9] For photocatalyzed difluoromethylation of other activated alkenes in flow, see: a) S. Sumino, M. Uno, T. Fukuyama, I. Ryu, M. Matsuura, A. Yamamoto, Y. Kishikawa, J. Org. Chem. 2017, 82, 5469; b) X.-J. Wei, W. Boon, V. Hessel, T. Noël, ACS Catal. 2017, 7, 7136; c) X.-J. Wei, T. Noël, J. Org. Chem. 2018, 83, 11377; d) Y. Nakayama, G. Ando, M. Abe, T. Koike, M. Akita, ACS Catal. 2019, 9, 6555. For photocatalyzed trifluoroethylation of styrenes in flow, see: e) L. M. Kreis, S. Krautwald N. Pfeiffer, R. E. Martin, E. M. Carreira, Org. Lett. 2013, 15, 1634.

[10] For a recent example of visible-light-mediated iodoperfluoroalkylation of alkenes and alkynes, see: C. Rosso, J. D. Williams, G. Filippini, M. Prato, C. O. Kappe, Org. Lett. 2019, 21, 5341.

[11] Examples of photocatalyzed hydrotrifluoromethylation of alkenes in batch: a) S. Mizuta, S. Verhoog, K. M. Engle, T. Khotavivattana, M. O'Duill, K. Wheelhouse, G. Rassias, M. Médebielle, V. Gouverneur, J. Am. Chem. Soc. 2013, 135, 2505; b) D. J. Wilger, N. J. Gesmundo, D. A. Nicewicz, Chem. Sci. 2013, 4, 3160; c) S. P. Pitre, C. D. McTiernan,
H. Ismaili, J. C. Scaiano, J. C. ACS Catal. 2014, 4, 2530; d) L. Zhu, L. S. Wang, B. Li, B. Fu, C.-P. Zhang, W. Li, W. Chem. Commun. 2016 52,6371 ; f) Q. Lefebvre, N. Hoffmann, M. Rueping, Chem. Commun. 2016, 52, 2493; g) Y. Cheng, S. Yu, Org. Lett. 2016, 18, 2962; h) T. Yajima, S. Shigenaga, Org. Lett. 2019, 21, 138.

[12] Examples of photocatalyzed trifluoromethylation of alkynes in batch: a) N. Iqbal, J. Jung, S. Park, E. J. Cho, Angew. Chem. 2014, 126, 549; Angew. Chem. Int. Ed. 2014, 48, 539; b) Y. Cheng, S. Yu, Org. Lett. 2016, 18, 2962; c) T. Yajima, M. Ikegami, Eur. J. Org. Chem. 2017 2126; d) Y.-Y. Ren, X. Zheng, X. Zhang, Synlett 2018, 29, 1028.

[13] M. Daniel, G. Dagousset, P. Diter, P.-A. Klein, B. Tuccio, B.; A.-M. Goncalves, G. Masson, E. Magnier, Angew. Chem. 2017, 129, 4055 Angew. Chem. Int. Ed. 2017, 56, 3997.

[14] a) A.-L. Barthelemy, B. Tuccio, E. Magnier, G. Dagousset, Angew. Chem. 2018, 130, 13986; Angew. Chem. Int. Ed. 2018, 57, 13790; b) A.-L. Barthelemy, B. Tuccio, E. Magnier, G. Dagousset, Synlett 2019, 10.1055/s-0037-1611785.

[15] The reaction was also optimized using classical batch conditions. See the Supplementary Information for more details.

[16] As depicted in ref 13, PhS. radical is in situ generated from sulfilimino iminium 1. An alternative mechanism involving $\mathrm{PhSH}$ as HAT reagent could not be ruled out. For a similar report in batch, see: W. Huang J.Chen, D. Hong, W. Chen, X. Cheng, Y.Tian, G. Li, J. Org. Chem. 2018, 83, 578 . 
